\title{
«El Evangelio puede matar» \\ Análisis del preámbulo hermenéutico de la anti-cristología de Juan Luis Segundo
}

\author{
MARÍA EugENIA CELLI \\ Universidad Católica Argentina \\ meugeniacelli@gmail.com
}

\begin{abstract}
Resumen
Nada nos exime a los hombres y mujeres de hoy de aquella advertencia paulina recaída sobre «la letra que puede matar». Juan Luis Segundo S.J., teólogo latinoamericano de la liberación, es quien con sensibilidad y lucidez ha podido detectar en el acceso de sus contemporáneos a los evangelios y, por ellos, a la figura de Jesús de Nazaret este inminente peligro. En vista de tal problemática y con el fin de actualizar un Evangelio liberador se resuelve a elaborar, en su principal obra cristológica El Hombre de boy ante Jesús de Nazaret, un extenso preámbulo hermenéutico. A él nos abocamos, como objeto de análisis del presente artículo, con el fin de sistematizar las complejas tareas hermenéuticas que propone y de establecer la originalidad de su labor teológica entendida como anti-cristología.
\end{abstract}

Palabras claves: Jesús de Nazaret, cristología, evangelio, hermenéutica, liberación, círculo hermenéutico.

\section{"Gospel gives death » \\ Juan Luis Segundo's anti-christology's hermeneutic preamble analysis}

\begin{abstract}
Contemporary men and women are not exempt form that Pauline warning about «letter that gives death». Latin American liberation theologian, Juan Luis Segundo S. J., has sensibly and brilliantly detected this imminent danger in his contemporaries access to gospel and, through it, to Jesus of Nazareth's figure. In view of such problems and in order to update a liberating Gospel, be decides to elaborate, in his principal christological work «El Hombre de hoy ante Jesús de Nazaret», an extensive hermeneutic preamble. Such preamble is this article's object of analysis, to which we dedicate with the purpose of systematizing the complex hermeneutic task that he proposes and to establish the originality of his theological work, understood as anti-christology.
\end{abstract}

Key words: Jesus of Nazareth, christology, gospel, hermeneutics, liberation, hermeneutic circle.

Licenciada en Teología Dogmática por la Universidad Católica Argentina (UCA), obtuvo el grado académico con una tesis titulada: "Iuan Luis Segundo: la carne de una teología rioplatense y latinoamericana. Lectura y análisis de cuatro ejes temáticos de su pensamiento teológico". Actualmente es Profesora de Teología Fundamental y Dogmática en la Facultad de Ciencias Sociales y Económicas de la UCA. Recientemente ha colaborado en la reedición de las Obras selectas de Juan Luis Segundo en el marco de la Biblioteca testimonial del Bicentenario con unas palabras liminares: "Presentación de Juan Luis Segundo" (2010). 


\section{Introducción}

Juan Luis Segundo ${ }^{1}$ reconoce que el estudio acerca de Jesús de Nazaret llegó a su edificio teológico en una etapa avanzada y madura de su pensamiento ${ }^{2}$. Esto hizo posible que los contenidos, los esfuerzos metodológicos y lo analítico que recorre la totalidad de su obra se condensaran y profundizaran en su cristología como un lugar privilegiado de síntesis.

Asimismo, no es casual el hecho de que el tiempo de elaboración dedicado a su primera obra cristológica, El Hombre de hoy ante Jesús de Nazaret (Segundo, 1982), coincida con ese arco temporal de los años 1973-1982, en donde las circunstancias políticas ciñeron a la vida intelectual del país oriental en el silencio y el terror ${ }^{3}$. Ese clima de desconcierto político, económico y social, unido al convencimiento popular de que los testigos y referentes de ciertos valores humanos habían sido silenciados definitivamente y de que todas las luchas de liberación habían sido clavadas en esa cruz que aniquila, fue lo que llevó al jesuita uruguayo a emprender una tarea teológica de esperanza, dando cuenta de un testigo y de una vida que triunfa más allá de toda derrota aparente.

Decidido a perseguir este fin se abocó a investigar exhaustivamente el modo de ofrecer a todo hombre con fe e ideología, con evangelio y política un acceso fiel y actualizado al Nazareno para descubrir que es posible, aún en el hoy más conflictivo, oír hablar en una lengua cercana y vital de esa liberación real y profunda del hombre que sufre por las injusticias que lo aquejan.

1 Juan Luis Segundo nació en Montevideo, Uruguay en 1925. Inició su marcha teológica y pastoral en 1941 cuando ingresó a la Compañía de Jesús en su país. Años más tarde y tras el tiempo de formación, el jesuita uruguayo se destacó hasta su muerte (1996), en el ámbito latinoamericano, por una cuantiosa producción editorial que reúne más de 15 obras publicadas en varios tomos, traducidas a distintas lenguas, y un centenar de artículos y seminarios. De ellos, asombra actualmente la multiplicidad de abordajes y de ejes temáticos que este pensador logró poner en juego con su propuesta teológica. Para mayores referencias de su biografía intelectual, cf. Celli, 2010: IX-XXIV.

2 Así lo confiesa el jesuita uruguayo en la reedición revisada y aumentada de su obra Teología Abierta. A la cual le añadió un tercer tomo titulado Reflexiones críticas en donde asume la tarea de pensar cuestiones cristológicas. Cfr. Segundo, 1984: 35.

3 Acerca de la amenaza latente a su propia labor intelectual, J. L. Segundo relata en una entrevista: «De modo que es muy evidente que entre las actividades de la Iglesia, todas las que no fueron inocuas, masivas, antiguas, de procesiones o culto, comenzaron a ser vigiladas. (Es interesante saber que se nos pregunta con frecuencia sobre cosas que datan de mucho tiempo atrás, cosas que hicimos o dijimos o hemos escrito hace tiempo: señal que desde ese tiempo esas cosas se fueron vigilando, se fueron anotando y estudiando)» (Cabestrero, 1978: 66). 
En este contexto de sufrimiento y opresión Juan Luis Segundo advierte, con su habitual sospecha crítica, que el creyente medio recurre a los evangelios en busca de criterios práxicos inmediatos y de soluciones efectivas que, a modo de recetas o fórmulas, se apliquen sobre las problemáticas que lo acucian en su cotidianeidad humana ${ }^{4}$. Este acceso a los evangelios y, por ellos, a la figura de Jesús de Nazaret parece olvidar el problema hermenéutico previo que condiciona cualquier búsqueda y lectura. Por tal motivo, saltearse esta dificultad o subestimar la seriedad de la problemática del acceso a los evangelios equivale, para Segundo, a tomar el texto bíblico por mera letra. Lo cual, de acuerdo a la advertencia paulina que asegura que la letra mata y sólo el espíritu vivifica (2Co 3, 6b), implica para el creyente que el Evangelio también puede matar (Segundo, 1986: 473-474).

Nada indica a priori que las palabras de Jesús y, más explícitamente, las de Pablo sobre el peligro del recurso a la 'letra muerta', no se vuelvan a repetir, por lo menos en cierta medida, con la letra de los evangelios. Se acude a veces a ellos no para 'inspirarse' en contacto con lo inspirado, sino por una seguridad infantil. Como el joven al 'depósito' de las consignas de los padres. Es decir, esquivando el riesgo sano de interpretar a Jesús de nuevo frente a problemáticas igualmente nuevas. Ante las cuales, las respuestas de Jesús, tomadas a la letra, traicionarían su Espíritu. Se las consideraría como algo dotado mágicamente de verdad. Y ello terminaría llevando a dar, en nombre de Jesús, soluciones inhumanas (cf. GS 11) (Segundo, 1982b: 16).

América Latina ha experimentado de manera aguda las consecuencias de un Evangelio predicado, enseñado y orado como letra que mata. Repetidas veces en la obra segundariana se acusa como prueba más palpable de ello la inequidad del continente americano, la experiencia de una pobreza sin cambio y la nula transformación cristiana de los ámbitos sociales y políticos. A causa de ello, y según el juicio de nuestro autor, los latinoamericanos encarnamos la paradoja de ser un continente mayoritariamente cristiano, lo que significa haber sido nutridos por la letra del Evangelio, y mayoritariamente pobre, lo que revela la injusticia social e inequidad antievangélicas (Segundo, 1986).

\footnotetext{
4 Es interesante advertir cómo ya en el Encuentro Teológico Latinoamericano de 1975 Segundo da prueba de esta preocupación teológica en función del contexto en el que se halla enmarcado. Así sentencia: «...la praxis no se ilumina por ninguna lectura fragmentaria de la Palabra de Dios. La Palabra de Dios no da recetas históricas para iluminar la praxis; no podemos sacar una sola Palabra del Evangelio para resolver un problema actual» (Segundo, 1975: 100).
} 
En este sentido, la realidad nos devuelve la urgencia práxica, antes que especulativa, de elaborar un trabajo hermenéutico previo al acceso a los evangelios y a la figura de Jesús que alumbre por fin para América Latina la tan esperada cristología de la liberación.

...se ha observado, a manera de crítica, que esa pretendida teología comprensión de la fe- latinoamericana no ha querido o, más probablemente aún, no ha osado o no ha podido estructurar un modo de pensar propio, coherente y sistemático sobre Jesucristo. Dicho en palabras más técnicas: que a la teología latinoamericana, llámese o no teología de la liberación, le falta una «cristología» (Segundo, 1982b: 27).

Atendiendo a esta urgencia práxica y en vistas de la complejidad del pensamiento de Juan Luis Segundo, nos proponemos a partir de su principal obra cristológica, El Hombre de hoy ante Jesús de Nazaret (Segundo, 1982): 1) sistematizar en tres tareas fundamentales los preámbulos hermenéuticos de la anti-cristología de Segundo, entendiendo que ellos posibilitan de un modo liberador el acceso a Jesús de Nazaret por medio de los testimonios neotestamentarios, y 2) presentar en tres notas distintivas la particularidad de un trabajo cristológico enunciado como anti-cristología.

\section{Preámbulos hermenéuticos para el acceso a Jesús de Nazaret}

Juan Luis Segundo es un teólogo calificado por sus propios colegas de «emborrachadoramente analítico» (González Faus, 1989: 14), «insobornablemente crítico» (Jiménez Limón, 1990: 27), tendiente a «entretenerse en meandros minuciosos» (González Faus, 1985: 265) y con una escritura que «siempre evitó el camino más fácil» (De Santa Ana, 1997: 70), lo cual nos revela el carácter de un autor escurridizo y de difícil acceso. Esto mismo se comprueba en la obra cristológica que mencionábamos, de tres tomos y de una extensión de más de mil páginas. La cual exige al lector, no sólo la concentración de varias herramientas y recursos intelectuales, sino el haber comprendido o intuido el sistema que el jesuita uruguayo construye y del que hace depender todo su edificio reflexivo. En la teología de Segundo, la tarea de analizar sólo un tema o una obra de forma aislada o inconexa, se vuelve una traición a la misma intención de su gestador. Este punto es importante porque explicará, en razón del temple complejo y extenso de la materia, nuestra opción metodológica de reunir y sistematizar las 
numerosas aristas de su preámbulo hermenéutico en tan sólo tres tareas principales.

De modo sintético las enunciamos: la primera tarea consiste en lograr la actitud antropológica indispensable que debe asumir el sujeto que pretende acceder a una lectura actualizante y genuina de los testimonios neotestamentarios. La segunda invita a adquirir una triple conciencia hermenéutica por la que se adviertan ciertas distancias y cercanías no siempre visibles para el creyente. $\mathrm{Y}$, finalmente, la tercera tarea pretende ofrecer una clave hermenéutica adecuada y equilibrada que, a modo de herramienta, dé finalmente con el Nazareno desde un mundo particular y propio de intereses subjetivos. En el desarrollo de estas tareas observaremos cómo éstas hacen referencia, de manera particular, a los aspectos hermenéuticos emanados de lo antropológico, de lo gnoseológico y de lo metodológico.

\subsection{Actitud hermenéutica del sujeto (Aspecto antropológico)}

Juan Luis Segundo, que no oculta su gran entusiasmo por escribir una cristología para ateos reales (1982b: 25), afirmará en las primeras páginas de su anti-cristología que la actitud hermenéutica óptima para acceder a los evangelios es la del ateo. $\mathrm{Y}$ esto se debe a que el ateo no cuenta con una fe religiosa, sino tan sólo con un mundo de valores humanos desde los que estructura su existencia y a los que decide apostar su vida. A esta apuesta humana el jesuita uruguayo la denomina: fe antropológica.

En este sentido, a los creyentes que quieran acceder al Evangelio de un modo auténtico se les propone convertirse en ateos potenciales. Ateos, no en el sentido lato de postular la no existencia de Dios, sino en una dirección actitudinal en la que se invita a operar una epojé de la fe religiosa para que: por un lado, prime en el sujeto hermenéutico aquellos valores humanos que estructuran su mundo de sentido y, por otro, para que evite ese movimiento mecánico, masivo y mortífero de hacer una apuesta hacia un contenido religioso por el solo hecho de haber sido individualizado como «sagrado» o «cristiano».

De no asumir la condición de ateo potencial, el riesgo que se sigue cuando se antepone la fe religiosa al encuentro con Jesús de Nazaret es el de creer en un Dios, aún cuando éste niegue los valores humanos constitutivos del sujeto, por el sólo hecho de ser presentado como aquello que debe creerse o por ser apresuradamente identificado con lo Absoluto y lo divino. Para Segundo creer en Dios desde la sola fe religiosa, sin involucrar el propio mundo axiológico, no sólo genera a 
nivel de la vivencia cristiana un divorcio irresoluble entre fe y vida; sino que además, en el aspecto teológico, roza el pecado de idolatría 5 .

Pero, por otro lado, nos advierte que quien asume la actitud hermenéutica que él propone corre otro riesgo, no menos importante, que consiste en la posibilidad de no creer en un Dios que nuestros valores humanos juzgan inauténtico. Es decir el riego de un ateísmo real.

Quien se decide a correr este último riesgo, está en condiciones hermenéuticas de acceder al mensaje de Jesús ya que la fe religiosa no se impone a la fe humana, sino que la supone y se construye sobre lo que ésta postula. En cambio, el que queda al reparo de su sola fe religiosa, cree en Dios religiosamente pero no humanamente. En definitiva para Segundo, el costo que paga el creyente imposibilitado de un ateísmo potencial, es el sacrificio de su propia humanidad y la imposibilidad de acceder genuinamente a la figura de Jesús:

Para quienes el riesgo de «no creer» en Dios sea más grande que el de creer «en un Dios que no es», Jesús no será jamás accesible. Y este libro habrá sido escrito en vano. Por eso decíamos que un ateísmo «potencial», es decir, la aceptación seria del ateísmo como posibilidad frente a Jesús es una condición hermenéutica ineludible. Prescindiendo de que ésa sea la condición de toda hermenéutica de elementos religiosos (...), la exige concreta, históricamente, Jesús de Nazaret (Segundo, 1982b: 26).

La fe antropológica, entonces, es condición necesaria para evitar un Evangelio que mata. Y esto es posible porque el ateo potencial hace que los valores humanos que lo configuran de manera propia lo capaciten para reconocer en un acontecimiento histórico la revelación del Absoluto. De hecho así ocurrió, para el jesuita uruguayo, en el Israel del siglo I: sólo aquellos que encarnaban humanamente los valores del reino, pudieron leer en Jesús una buena noticia, un Evangelio y por eso mismo una revelación de Dios. En este sentido, ese mundo de valores antropológicos es origen de la fe religiosa. En esta dirección Segundo propone:

Tomemos un caso imaginario y reduzcamos así al máximo sus elementos. Supongamos de antemano que Jesús dijo que él era Dios mismo hecho hombre $y$, por lo tanto, revelación divina directa. Supongamos, por otra parte, que, mediante técnicas más perfeccionadas que las actuales, pudiéramos ver y oír directamente a Jesús tal cual fue, y sin los

\footnotetext{
5 Las construcciones teológicas de Juan Luis Segundo han hecho del ateísmo y de la idolatría dos temáticas unidas recurrentemente en sus escritos. Al respecto, Sobrino, 1996: 3-10.
} 
intermediarios que lo interpretaron primero y luego hablaron y escribieron acerca de él. Pues bien, ¿qué nos dice el evangelio mismo sobre nuestras posibilidades de aceptar esa 'revelación' y de determinar sobre ella nuestros valores? Lo que ya sabemos, (...) que sólo quienes tenían ya esos valores reconocieron a Jesús como revelación de Dios (Segundo, 1982a: 85).

En síntesis, el ateísmo potencial se vuelve condición hermenéutica del creyente que lo obliga a anteponer los valores humanos a su fe religiosa hasta convertirlos en criterios de la aceptación del mensaje de Jesús tal como lo hicieron sus contemporáneos. De este modo, «...la manera más 'realista' de acceder a Jesús, la que corresponde a la de sus primeros testigos, es hoy la de los 'que han suspendido provisionalmente su juicio definitivo acerca de Jesús' hasta ver lo que hace, lo que dice y lo que significa ese hombre» (Segundo, 1982b: 31).

\subsection{Conciencia hermenéutica de tres distancias (Aspecto gnoseológico)}

Una vez que el creyente ha adquirido una posición de ateo potencial, Juan Luis Segundo refiere la necesidad de apropiarse a nivel intelectual de una triple conciencia hermenéutica que acompañe el acceso a los evangelios. Ésta se orienta a detectar ciertas distancias hermenéuticas que le advierten los límites gnoseológicos, los caminos sin salidas y las posibilidades reales de su lectura. Presentamos a continuación el desarrollo de las tres distancias necesarias para la labor hermenéutica propuesta.

\subsubsection{Distancia entre el Jesús-Jesús y el Jesús testimoniado}

Segundo apela a recuperar una conciencia de la distancia hermenéutica que existe entre el judío Jesús, que vivió en el siglo I, que recorrió los caminos de Galilea y más tarde de Jerusalén, que enseñó e interpretó su tradición, que comió y bebió con sus discípulos, que interesó a las multitudes al punto de que éstas hicieron una apuesta por él; y aquél Jesús al que nosotros tenemos acceso mediante los testimonios que nos llegan de él. Es decir, una distancia entre el JesúsJesús, irremediablemente perdido para nosotros, y el Jesús interpretado al que tenemos acceso por los evangelios.

En este sentido, por ser histórico, Jesús sufre los mismos condicionamientos que cualquier sujeto del pasado. Volviéndose imposible obtener un cuadro totalmente acabado del Jesús-Jesús. Lo cual obliga al creyente a deshacerse del espejismo de llegar a obtenerlo algún 
día. El hombre de hoy ante Jesús debe ser consciente de la mediación interpretativa que establece un puente entre él y el Nazareno. Al punto de cristalizar esta conciencia en la afirmación de que: «...el Jesús no interpretado por nadie no existe. No existe un Jesús-Jesús. Lo que, con razonable certeza, podemos atribuirle históricamente es, también ello, interpretación» (Segundo, 1982b: 35-36).

Recuperar la conciencia de esta distancia hace posible un nuevo acercamiento al Nazareno siempre mediado por el cúmulo de interpretaciones que aúna el nuevo testamento. Con tal fin, Segundo (1982b: 51) le propone al creyente incorporarse a una especie de túnel del tiempo, por el que se haría posible un diálogo con el mundo vital judío del siglo I que experimentó el mismo Jesús. En este sentido, la invitación de Segundo no quiere tomar como punto de partida, en lenguaje clásico, ni al Jesús histórico ni al Cristo de la fe; sino que, manteniendo la tensión que provee la distancia hermenéutica enunciada, opta por un acceso a Jesús desde la matriz de la historia inserta en un proceso educativo - y por ello interpretativo- de aprender a aprender. Analicemos detenidamente qué implicancias conlleva esta propuesta segundariana:

- Ante todo, la decisión de Juan Luis Segundo de no empezar su reflexión cristológica ni por el Jesús histórico ni por el Cristo de la fe, guarda relación con su deseo de que la fe humana del ateo potencial sea el punto de partida inicial y real de cualquier inserción que el hombre de hoy pueda hacer a la figura del Nazareno.

- Asimismo la idea de incorporarse en ese túnel del tiempo esconde una diferencia, pocas veces descubierta, en relación al abordaje latinoamericano de Jesús que marca su especificidad frente al de la teología europea. Ésta última, motivada principalmente por la significación de la identidad jesuánica, suele embarcarse en la búsqueda del Jesús histórico diferenciándolo del Cristo de la fe. De modo diferente, la teología latinoamericana de la liberación recurre a la historia de Jesús, sin aislarlo del tamiz de los testimonios pos-pascuales ni de las preguntas del hombre actual, ya que su pretensión no es correr tras la identidad del Nazareno, sino dar con ese proyecto de seguimiento que permita al contemporáneo implicarse en él como un verdadero discípulo. Debemos entroncar la propuesta del jesuita uruguayo en esta perspectiva ${ }^{6}$.

\footnotetext{
Para profundizar las notas y los fundamentos de esta diferencia remitimos al artículo de Kuhn, 1999: 32.
} 
- La conciencia de la distancia hermenéutica planteada, permite que el hombre de hoy tenga «la posibilidad de 'vivir' experiencias ajenas sin caer en la arbitrariedad total»(Segundo, 1982b: 51). Delineando, para ello, las tareas de traducir ${ }^{7}$ y de traspasar las barreras del espacio y del tiempo, pero sin abandonar los propios entusiasmos e inquietudes, sino colocándolos como guías en la traducción (Segundo, 1982b: 46). Con ello el jesuita uruguayo cree volver a reconstituir la alianza, a veces rota por miramientos de imparcialidad y por anhelos de mayor cientificidad, entre cristología y soteriología. Segundo señala críticamente que en múltiples oportunidades los teólogos que propician al Jesús histórico parecen desalentar las ansias soteriológicas de quien se orienta en su búsqueda, creyendo que en el sacrificio de los anhelos y deseos personales se esconde la garantía de objetividad.

- Por último, la posibilidad de incorporarse en ese túnel del tiempo descansa en la forma particular que tiene Juan Luis Segundo de entender la historia y la revelación como de un proceso pedagógico evolutivo. En este sentido, la historia no es simplemente un escenario montado sobre el cual el hombre existe, sino que es el producto de su capacidad de significación. Así desde el momento en que hay un sujeto capaz de proporcionar un hilván significativo a la cantidad de sucesos que acontecen es que hay historia. Ello se potencia si a la historia le sumamos la revelación, ya que dicho hilván estará determinado por una significación con acento teológico. Esta definición de la historia incluye la comprensión de una memoria colectiva de la especie, en donde cada uno de los sujetos es insertado, no a un cúmulo de información, sino a una trama narrativa que se brinda como ocasión y medio de aprendizaje (Segundo, 1971a: 15).

...la memoria y la pedagogía colectiva tienen una decisiva función en el mismo proceso de la revelación: hacen que cada generación nueva no tenga que comenzar desde cero su aprendizaje (de segundo grado). Recordando y re-asumiendo, de un modo vivido y asimilado a la propia identidad colectiva, las experiencias pasadas de un proceso donde la búsqueda, las soluciones y los desafíos de la historia convergen, cada

Esta es una de las diferenciales que Juan Luis Segundo mantiene con Bultmann, y que muchos críticos de la teología segundariana no supieron ver con claridad. El jesuita entiende, a diferencia del alemán, que no es lícito suprimir lo mítico ya que es fundamental hacerse de ese lenguaje de orden icónico y traducirlo, para que sea igualmente significativo en nuestro contexto actual. Para este punto, Segundo, 1982b: 52-59. 
generación es lanzada hacia una madurez más cabal y hacia una nueva, más profunda y más rica verdad (Segundo, 1992: 457).

En ese proceso pedagógico el sujeto advierte una diferencia de niveles en relación con la verdad. En un plano primario la verdad es entendida como aquella que transparenta una exactitud material con los hechos acontecidos, pero en uno superior la verdad exige poseer un criterio hermenéutico que permita abrir el sentido de los acontecimientos. A la primera forma se la denomina proto-aprender y a la segunda, requerida para el acceso al Nazareno, aprender a aprender (Segundo, 1989: 85).

\subsubsection{Distancia entre los testimonios neotestamentarios de Jesús}

Como ya referimos, la cristología del último siglo ha asistido a la búsqueda entusiasta del Jesús histórico que ha llegado, con razonable certeza, hasta ciertas palabras y hechos de Jesús. Para Segundo este descubrimiento reviste importancia, no tanto por el conocimiento de las mismísimas palabras de Jesús ${ }^{8}$, sino porque este hecho teológico se ofrece a la conciencia del cristiano como una prueba que permite dar cuenta, no sólo de la distancia existente entre Jesús-Jesús y sus intérpretes, sino también del espacio creador en el que éstos últimos desarrollaron los testimonios que han llegado hasta nosotros. Esta distancia creativa nos otorga la conciencia refleja de una nueva distancia hermenéutica: la que existe entre cada uno de los múltiples testimonios. Cada uno de ellos abordó la figura de Jesús desde su particular fe antropológica, siendo que, por eso mismo, ninguno lo agotó plenamente.

Estableciendo cierta distancia entre Jesús y su intérprete, es posible descubrir mejor el trabajo creador de éste, sus motivos de interés en Jesús, su problemática y cómo el hombre Jesús lo iluminó. Mateo, Macos, Pablo, se vuelven así de meras pantallas colocadas entre Jesús y nosotros, testigos en sí mismos $-\mathrm{y}$ no sólo de Jesús- personas reales con su propio contenido significativo, contenido que los vuelve a su vez, interesantes para nosotros (Segundo, 1982b: 34).

8 Si bien Segundo reconoce la riqueza de la investigación sobre el Jesús histórico, también señala con gran tino pastoral la imposibilidad del cristiano medio de acceder a los resultados de dichos descubrimientos. En este sentido: «...cualquiera que se preocupe de la difusión del mensaje de Jesús entre los hombres debe saber que la inmensa mayoría de la humanidad no leerá jamás, no digamos los cuatro evangelios: ni siquiera uno de ellos. ¡Cuánto menos las toneladas de papel impreso que son menester hoy para tratar, tras minuciosas investigaciones, de llegar a las mismísimas palabras que usó Jesús!» (Segundo, 1984: 38). 
Sin duda este abordaje, no sólo resguarda la igual dignidad de los testimonios, sino que también despeja aquella ilusión piadosa de hallar un único testimonio que haya interpretado correctamente a Jesús. Para Segundo: «Esa distancia recobrada entre el personaje histórico y sus intérpretes abre, de esta manera, un espacio para mi propio diálogo dos mil años después con Jesús de Nazaret» (Segundo, 1982b: 35).

¿Qué ha hecho el testimonio con la figura de Jesús para posibilitar al hombre de hoy su acceso? Segundo (1989: 68) entiende que la tarea de los testigos ha consistido en puntear la trama caótica de los hechos pasados. Lo que significa colocar signos de puntuación en la materia informe de lo que acontece, para convertir esa sucesión de hechos en historia significativa. El sentido y el valor regente dado a éstos se convierten en normativos para el grupo humano que recibe el testimonio, en razón de que le ofrecen un porqué que da sentido y unidad al conjunto disperso y heterogéneo de acontecimientos. En este sentido, Segundo (1989: 65) los califica de hechos paradigmáticos que logran ejercer un efecto normativo en las interpretaciones históricas posteriores. Para las generaciones futuras estos hechos significativos o paradigmas se vuelven en su «hoy» puntuaciones históricas referenciales que conducen la interpretación actual de sus propios acontecimientos y que posibilitan nuevas formas de puntuar.

Cuando se accede a los testimonios neotestamentarios desde este presupuesto se advierte que no hay una única forma de puntuar los acontecimientos, sino que conviven en el interior del testamento numerosos relatos con puntuaciones significativas distintas. Lo cual pone de manifiesto que en el testamento cristiano, y extensivamente en toda la biblia, se albergaron distintas formas de puntear que supieron convivir pacíficamente entre sí.

$\mathrm{Al}$ hombre de hoy le corresponder mantener esa respetuosa distancia hermenéutica entre cada uno de los testimonios y no hacer de ellos una realidad monolítica que sucumba ante concordismos bíblicos estériles o ante la tentación de elaborar una cristología única. Este esfuerzo por mantener la pluralidad le garantiza la posibilidad de volver a puntear desde su actualidad lo acontecido en el siglo I y la de reconstruir creativamente el mensaje del Jesús. El jesuita define esta tarea como el arte de crear evangelio para el hoy y la considera como una tarea inalienable del cristiano (Segundo, 1982c: 803).

Ahora bien, esta posibilidad de crear evangelios ¿no daña el valor de depósito y el carácter revelado de los cuatro canónicos? Segundo responde: 
El hecho de que el 'depósito' se cierre no significa, por tanto, que termine también el proceso por el cual Dios, mediante el Espíritu de Cristo, nos conduce a toda verdad. ¿Por qué entonces se cierra el «depósito» mientras la educación de Dios continúa? Sin duda porque también en el proceso educativo de cada hombre en un momento dado éste debe salir de lo 'depositado' en las consignas paternas o maternas. Y no para negarlas, sino para confrontarlas con los desafíos de la vida. Allí, errando y corrigiendo errores, lo depositado se hará más hondamente vida y posibilidad de creación (Segundo, 1982b: 16).

En esta misma línea, la multiplicidad de testimonios mediadores de nuestro acceso a Jesús tienen una función pedagógica esencial, ya que como maestros de camino nos evitan empezar de cero la tarea de puntear/interpretar al Nazareno y nos obligan a situarnos en la lógica de aprender a aprender. Marcos, Mateo, Lucas, Juan, Pablo y otros nos proveen sus preguntas y sus respuestas, sus problemas y sus soluciones, sus anhelos y sus esperanzas cumplidas como un impulso renovado para crear nuestros evangelios cada vez más maduros y cada vez más abiertos a esa verdad hermenéutica que se ofrece.

\subsubsection{Distancia entre Jesús de Nazaret y el acceso subjetivo del hombre de hoy a su figura}

El creyente, implicado en esta tarea debe considerar una nueva distancia que se establece entre Jesús de Nazaret y el acceso personal y subjetivo que él es capaz de realizar a su figura.

Ciertamente, no es la misma distancia que establecimos entre el Jesús-Jesús y el Jesús testimoniado, ni la que advertimos entre los testimonios. Ante todo, porque nosotros no interpretamos a Jesús de primera o segunda mano, sino que hemos sido sometidos a un proceso pedagógico de más de veinte siglos en donde el Jesús al que accedemos se halla ya interpretado desde hipótesis hermenéuticas particulares. Por otro lado, a diferencia de las comunidades que gestaron los testimonios, nosotros no podemos apelar a una isomorfia de condiciones contextuales, porque más allá de que muchas de ellas no hayan tenido experiencia directa del Nazareno, sí han tenido - en razón de la cercanía temporal- vivencia de las costumbres, el lenguaje, la dinámica social y la política. Es decir, compartieron un mismo ámbito vital, totalmente desvanecido para nosotros. De ahí que se imponga al hombre del siglo XXI el traducir lo pasado para hacerlo comunicable en la actualidad.

Para Segundo la distancia que nos ocupa, guarda relación con las condiciones y condicionamientos que el hombre actual posee a la hora 
de volver a interpretar al Nazareno. En primer lugar, establece que todo proceso hermenéutico parte de una pre-comprensión, como forma propia que tiene el hombre de acercarse a cualquier testimonio, texto o persona del pasado. Este punto de partida se vuelve peligroso sólo cuando no es lo suficientemente advertido y criticado como parcialidad subjetiva desde la cual el intérprete se asoma a lo dado. En este sentido, el jesuita uruguayo no teme confesar que, está presente en este abordaje, una dosis de inevitable relativismo, inherente a todo proceso educativo. Pero, también señala, que es Dios mismo quien ha decidido plegarse a la forma humana de conocer y pagar así el precio de cierto relativismo con tal de preservar nuestra propia libertad (Segundo, 1982b: 56-57).

La pre-comprensión es, por un lado, condicionante y limitante de la lectura; pero, por otro es posibilitadora y necesaria de una auténtica comprensión humana. Una «pre-comprensión determinada puede ser la condición para la comprensión objetiva más cabal de un mensaje» (Segundo, 1982b: 57).

Ahora bien, no todas las pre-comprensiones son siempre equilibradas, puede haber sujetos que intenten acceder al Evangelio con pre-comprensiones erradas, desvirtuadas y espurias. Es aquí donde el Evangelio es capaz de protestar:

Es cierto, por ejemplo, que se le pueden plantear preguntas erradas al evangelio, tales como la manera de justificar la explotación de unos hombres por otros. Pero no es menos cierto que el evangelio, aún leído desde ese punto de vista deformante, tiene su propia consistencia y es muy capaz de protestar. No es pura y simplemente deformado: lucha contra la deformación previa y apela a una 'conversión' que se volverá, a su vez, precomprensión para una nueva lectura y comprensión (Segundo, 1982b: 57$58)$.

Hay en lo expuesto una circularidad establecida entre precomprensión, lectura, comprensión y nueva pre-comprensión, nueva lectura y nueva comprensión. De este modo, nuestro autor adopta la idea de una circularidad hermenéutica como posible acceso del hombre de hoy a Jesús de Nazaret. Tanto en sus obras cristológicas, como en una obra específicamente metodológica (Segundo, 1971b), analiza la posibilidad de incorporar al círculo hermenéutico como método (cfr. Segundo, 1971b: 13) para la cristológica y la reflexión teológica en general, estableciendo las diferencias con el círculo bultmaniano ${ }^{9}$ y la especificidad de su propia propuesta.

$9 \quad$ Más allá de las extensas anotaciones realizadas por Segundo apelamos a la sintética comparación que establece Fernando Khun. Para él se advierte una triple diferencia 
Sólo el hombre de hoy, interesado por aquél galileo del siglo I puede, acceder a dicha circularidad interpretativa porque es el único capaz de recorrer los cuatro momentos de este círculo (Segundo, 1971b: 14). Analicemos brevemente en qué consisten estos cuatro peldaños del círculo propuesto por Juan Luis Segundo:

- El primer momento supone la experiencia que el sujeto recaba de su propia realidad social, económica, cultural, política y religiosa. Ésta sólo es posible si se ha asumido, previamente, un compromiso preteológico ligado profundamente a los valores antropológicos. En este sentido, el sujeto inserto en el círculo debe adoptar una parcialidad concientemente aceptada ante la realidad que lo circunda. Esta es la piedra de toque de todo su método circular.

- En el segundo momento el jesuita vuelve activa esta toma de posición ante la realidad proponiendo una sospecha metodológica hacia todos los ámbitos de la cultura que produzcan mecánicas de opresión. Juan Luis Segundo entiende que la mediación óptima para encarnar esta sospecha es la que proporciona la praxis y el conocimiento político.

- El tercer momento pide la misma experiencia referida al inicio del círculo, sólo que ahora direccionada al interior de la realidad teológica. Aquí el compromiso pre-teológico se vuelve opción por el pobre que se traduce para el teólogo y el creyente en hacer de la teología un instrumento y un arma al servicio de una praxis radicalmente liberadora. Con este fin, se propone una sospecha exegética de las lecturas e interpretaciones bíblicas no liberadoras. Esto es, «desconfiar de las preguntas que se le suelen hacer, de las que parecen más naturales, más neutras, más científicas» (Segundo, 1977: 24).

- El cuarto momento, como réplica del segundo, produce una nueva hermenéutica de los textos bíblicos. En este último movimiento se aparta

entre los planteos bultmanianos y los de Juan Luis Segundo. Para el primero: 1) el Jesús histórico tiene una escasa significatividad para la fe, 2) es notoria la omisión de todo tipo de seguimiento e implicancia discipular en la obra del alemán y 3) se adivina un esfuerzo apolítico en sus reflexiones cristológicas. En cambio en la propuesta del jesuita uruguayo, en particular, y en la teología de la liberación, en general, se halla: 1) una búsqueda de lo histórico de Jesús con cierta preeminencia, 2) no hay una separación tajante entre el Jesús de la historia y el Cristo de la fe, lo que permite no sólo nutrirse de quién fue Jesús sino de cuál fue el proyecto al que hicieron apuesta sus discípulos, para continuar con él, y 3) el interés político y práxico que vertebra muchas de las búsquedas del hombre contemporáneo en Latinoamérica. Cfr. Khun (1999: 24-25). 
de toda teología que produzca lectura bíblicas atemporales e imparciales, volviendo a recordar la necesaria tarea del cristiano de aprender a aprender en función de la resolución de problemas históricos siempre nuevos y diversos. El deuteroaprendizaje, enmarcado en el círculo hermenéutico de cada creyente, despeja el literalismo bíblico y evidencia la necesidad de una creatividad subjetiva que brinde respuestas actualizadas a las situaciones vitales que se presentan. En esta dirección hermenéutica y actualizadora va su propuesta para la teología latinoamericana.

De este modo, la pre-comprensión del creyente, de la que hablábamos en el inicio, se forja en los tres primeros momentos del círculo. En esta instancia de pre-comprensión el creyente se lanza en busca de Jesús de Nazaret con su experiencia, su compromiso, su sospecha pero también con sus deseos, sus búsquedas, sus anhelos. Muchos de ellos genuinos y muchos otros necesitados de esa conversión paulatina que posibilita el círculo mismo. El hombre de hoy inserto en los testimonios neotestamentarios busca, por medio de ellos, a un Jesús ante el cual dialogar. A su vez, los relatos testimoniales, anclados en el proceso de aprender a aprender pueden corregir y afinar dicha precomprensión capacitando al sujeto para una búsqueda más genuina y profunda de la verdad.

Estas hermenéuticas emergentes posibilitadas por el cuarto momento del círculo se vuelven hacedoras de nuevas lecturas, las cuales sólo conservan su sello de actualidad si mantienen esa conciencia hermenéutica que señala la distancia entre la interpretación particular del sujeto y la realidad inagotable de Jesús de Nazaret. Esto mismo da lugar a una tarea siempre renovada e incesante de crear evangelios para hoy.

\subsection{La clave hermenéutica (Aspecto metodológico)}

En relación a la pre-comprensión, a la multiplicidad de lecturas surgidas del círculo hermenéutico y a las diferentes formas de abordaje que suscita el encuentro con el dato histórico de Jesús, el jesuita propone una herramienta interpretativa precisa para llevar a cabo este camino. Esta es la clave hermenéutica.

Es imposible para nuestro autor llegar a interpretar a Jesús, o a cualquier personaje del pasado, sin una clave que abra el camino de lectura e indique un horizonte de sentido. De hecho, si miramos hacia atrás descubrimos que, tanto los testimonios más antiguos acerca del Nazareno como los más contemporáneos, están sometidos a alguna 
clave hermenéutica ${ }^{10}$. En este sentido, y de acuerdo a lo establecido en la conciencia de la segunda distancia, el segundo testamento encarna una pluralidad interpretativa demostrada en la gran cantidad de títulos cristológicos y de figuras que se aplican al Nazareno.

Todos los escritos del Nuevo Testamento usan claves, y claves diferentes, para cobrar esa presa esquiva del sentido de Jesús. Así, títulos como nuevo Moisés, Hijo de Dios, el primogénito de entre los muertos, el sumo sacerdote único, el Verbo, son otras tantas claves que se han aplicado a él, con mayor o menor fortuna (Segundo, 1984: 117).

Esta pluralidad interpretativa revela un dato curioso acerca de la creatividad y la libertad de los autores bíblicos. Ellos, luego de la muerte y resurrección de su maestro no temieron al desafío interpretativo, que los ubicó en la difícil tarea de crear sentido a partir de la historia de Jesús. Prueba de ello son, para ir más allá de los evangelios, tanto el corpus paulino (Segundo, 1982b: 66) como el libro de los Hechos de los Apóstoles (Segundo, 1984: 115), los cuales no ahorraron ningún esfuerzo para leer la figura jesuánica desde una clave distinta a la que él mismo se adjudicó en su misión ${ }^{11}$.

En este sentido, todo testimonio neotestamentario es fruto de una interpretación surgida desde intereses, problemas y conflictos que logran proyectar sobre el Nazareno algunas cuestiones determinadas, al mismo tiempo que se silencian otras. De este modo, lo que hacen los hagiógrafos y las comunidades pos-pascuales es aplicar una hipótesis interpretativa nacida de su propio mundo para llevarla hacia la realidad histórica del Nazareno. Allí está el origen de la clave hermenéutica. Por eso, refuerza el jesuita que:

...es un puro espejismo tratar de acudir a los evangelios canónicos como si en ellos pudiéramos hallar un Jesús aún no interpretado. Como si el Jesús

10 Juan Luis Segundo, a pesar de establecer un punto de contacto entre los testimonios antiguos y las interpretaciones contemporáneas, también manifiesta alguna diferencia entre ellos. Los primeros transparentan sus claves y manifiestan su particularización sin temores, mientras que los segundos las ocultan bajo el velo de la objetividad y de lo universal aplicable a todo hombre.

11 Juan Luis Segundo advierte que después del acontecimiento de la resurrección, las comunidades cristianas sufren un desplazamiento en su mensaje: permutando el anuncio histórico de la llegada del reino por la cuestión teológica de la persona de Jesús. Con este desplazamiento los cristianos comienzan una profundización reflexiva acerca de Jesús y lo divino. Esto tuvo su plasmación en los escritos neotestamentarios con un lenguaje icónico característico, como el que demuestran los términos Señor, Hijo de Dios, Primogénito, Alfa y Omega, entre otros. 
de Marcos o de Juan no hubiera sido ya puesto en clave para solucionar problemas humanos, más cercanos sin duda al tiempo de Jesús, pero problemas humanos desde los cuales se procura penetrar en lo que él fue, hizo y dijo. Aun en lo que tienen de 'historia', los evangelios canónicos utilizan un procedimiento que ninguna historia significativa puede evitar: proyectar una hipótesis interpretativa desde nuestro mundo. Desde aquello que nos interesa. Aun sabiendo que la persona histórica no vivió lo que nos problematiza o, por lo menos, no lo vivió de la misma manera (Segundo, 1982b: 65-66).

Con ello, se entiende que no se trata de huir a la interpretación actualizante como garantía de fidelidad histórica, ni de repetir prolijamente lo que proporciona la investigación de las fuentes, sino de posibilitar una comprensión y sentido cabal de la figura del Nazareno para el hombre de hoy. De este modo, debe quedar claro que interpretar nada tiene que ver con inventar desde la nada, sino que se refiere al modo propio que tiene el hombre de aproximarse con sentido a las figuras del pasado. Por otro lado, nuestro teólogo advierte, sobre el desequilibrio que puede producir la ausencia de una «clave» o, mejor dicho, de la explicitación de los presupuestos con los que se llega a la lectura de Jesús. En muchas oportunidades se evidencia cómo ciertos a priori no explícitos manipulan y dirigen la exégesis y los datos de la investigación histórica, llegando a desdibujar los núcleos fundamentales de la figura de Jesús. De ahí la importancia de hacerse de una clave hermenéutica.

Pero ¿qué es la clave hermenéutica? Para ser precisos, Segundo (1984: 117) entiende que es: «un procedimiento hermenéutico o, para decirlo de una manera más simple, una red tendida desde nuestro presente hacia el pasado para capturar el sentido de un personaje o de una época». Esto significa que ella nos brinda un ángulo de visión desde donde abordar con actualidad la figura histórica de Jesús. A lo que debemos sumarle algunas notas que caracterizan y especifican la funcionalidad de la clave.

- En primer lugar, el jesuita indica que el valor de la clave reside en que ésta puede lograr una unificación coherente de los datos históricos a los que se arriba a partir de la investigación historiográfica. Con ella, la pluralidad de información adquiere organicidad y sentido, ya que se la ordena a partir de un tipo específico de lectura.

- En segundo término, la clave no es configurada azarosamente, sino a partir de dos elementos que confluyen en su elección. Por un lado, a 
partir del dato histórico que nos hace conocer el orden o el plano en que el personaje histórico invirtió su vida; y, por otro, la problemática contextual y actual del que interpreta. Éste proyecta inquietudes y preguntas desde la realidad que lo interpela, sin por eso hacer desaparecer el eje central sobre el que gira el sentido de esa figura histórica. Esta línea tan delgada, entre la fidelidad y la originalidad, entre lo que viene dado y lo propio, es la que se debe sostener a riesgos de crear un personaje a la medida de las necesidades de quien interpreta. Por tal motivo, Segundo presenta la clave como un presupuesto de lectura, similar al de una hipótesis que sólo es supuesta mientras los datos del pasado la sustentan, pero que debe ser abandonada en cuanto no tenga el soporte de la historia.

- En tercer lugar, el jesuita uruguayo establece que el dato histórico que debe primar en cualquier interpretación de Jesús - y por tanto en la clave que se elija- es el conflicto, que se agudiza con su mensaje y su praxis. Esta afirmación será fundamentada largamente a partir del análisis de los motivos de la muerte de Jesús, del vocabulario jesuánico presente en su predicación y atestiguado de modo múltiple por los evangelios y del interés suscitado en sus contemporáneos a partir de su figura.

- Finalmente, en cuarto término, se señala un límite para la lectura en clave. Si bien esta herramienta hermenéutica es necesaria, se debe tener en cuenta que no se puede reducir la totalidad de una vida a la lectura que propone una clave (Segundo, 1982b: 270). La hermenéutica ya nos advierte que la vida real de un personaje del pasado siempre excede cualquier tipo de lectura o interpretación posible sobre ella.

...siempre deberá tenerse presente, sin embargo, que una «clave » histórica nunca puede dar cuenta de todo un complejo ser humano (tanto en su lenguaje como en su actividad). Para que la historia cumpla su función es necesario usar tales 'claves' como hipótesis generales de trabajo. Pero también es menester recordar que ellas no lo explican todo. Sin 'claves', en cambio nada tiene acceso al sentido: los datos permanecen caóticos o casuales (Segundo, 1991: 176).

¿Cuáles son las claves hermenéuticas que elige nuestro autor para su anti-cristología? Él privilegia tres claves para interpretar a Jesús de Nazaret. Estas son la clave política, la antropológica y la evolutiva. Si bien, ya señalamos el hecho de que cada una de estas claves es elegida a partir de los intereses que configuran al hermeneuta y de los datos de la figura histórica, nuestro autor especifica una diferencia entre estas tres. 
La primera de ellas obedece primariamente a una recuperación de lo histórico del Nazareno. Según el aporte de la crítica histórica, la clave política es la misma clave en la que Jesús eligió vivir y morir. Con lo cual, esta clave está determinada primariamente por la figura histórica (Segundo, 1982b: 289) y sólo, secundariamente, por el intérprete. En cambio, las otras dos claves - la antropológica y la evolutiva-, aunque siempre en coherencia con el dato del Jesús histórico, deben considerarse como prioritariamente surgidas del contexto y del interés de quien interpreta y de su deseo actualizante ${ }^{12}$.

\section{La propuesta anti-cristológica de Juan Luis Segundo}

Para el final hemos dejado la clarificación de por qué Juan Luis Segundo se decide a elaborar una anti-cristología. La razón principal para ello reside en que nuestro autor tiene la necesidad de producir un logos antitético que se oponga al desarrollo de las actuales cristologías académicas. Su antí-tesis se expresa en tres tomas de posición cuyas notas delinea de una manera precisa y que nosotros resumimos entendiendo que: la primera, consiste en la negativa a reunir en una sola producción todos los materiales interpretativos acerca de Jesús (que generalmente en los manuales de cristología van desde los Sinópticos hasta Calcedonia); la segunda, plantea la negativa a adoptar como punto de partida la confesión de la divinidad del Nazareno, y la tercera, estipula la necesidad de no silenciar los propios compromisos humanos preteológicos y contextuales con los que comienza su labor interpretativa de Jesús. Estas tres negativas lo distancian de las cristologías académicas y lo sitúan en un lugar original de la producción cristológica. A continuación analizamos brevemente cada una de éstas.

- En primer lugar, nuestro jesuita manifiesta su negativa a reunir en un solo tratado la multitud de testimonios interpretativos referidos a Jesús. ¿Por qué? Principalmente porque la experiencia de las actuales cristologías le demuestra a Segundo que este «reunin» se transforma, progresivamente, en una tendencia a «unifican». Lo cual deriva en un empobrecimiento peligroso de los testimonios. En este sentido, el autor uruguayo decide que su producción será anti-cristológica por limitar su estudio a algunas creaciones cristológicas y por mantener la pluralidad de

\footnotetext{
12 De estas dos claves, nuestro autor especificará que, la clave antropológica surge del interés de Pablo; mientras que la evolutiva, en calidad de ensayo, nace de las inquietudes actualizantes de él mismo en cuanto intérprete de Jesús.
} 
abordajes hermenéuticos. De hecho su elección se restringe a la producción de los sinópticos, de Pablo y a cierto ensayo teológico elaborado desde el contexto evolutivo ${ }^{13}$. De estos testimonios se analizan los esquemas mentales, las claves hermenéuticas, los géneros literarios y el vocabulario empleado en cada una de éstas.

- En segundo lugar, el jesuita detecta que en la academia la mayoría de las cristologías clásicas comienzan identificando a Jesús con lo divino o con el mismo Dios. Lo que equivale, en términos segundarianos, a secuestrar la figura histórica del Nazareno bajo la multitud de interpretaciones que lo definen como Mesías o simplemente como Dios (Segundo, 1991: 115). Lo cual deriva en una comprensión cristológica de categorías abstractas y atemporales. En cambio, su anti-logía, si bien no pretende negarle a Jesús su identidad divina, sí decide ubicarse en un momento anterior a esa identificación, en aquella instancia en que aún el Nazareno no ha sido objeto de proclamación mesiánica ni trascendente.

En este sentido, opta por tomar a Jesús como hombre ambiguo, limitado y determinado por sus circunstancias históricas, entendiendo qué fue lo primero que despertó el interés de sus contemporáneos por este artesano galileo del siglo I. Ellos pudieron advertir que su mensaje y su praxis vehiculizaban valores y significados afines a sus propios mundos de sentido (fe antropológica), tocando sus fibras más íntimas y posibilitando una nueva esperanza.

¿Por qué se opta por este comienzo? Ante todo porque intenta evitar que, en su actualización del evangelio, surjan el tipo de preguntas que conducen a saber qué es Jesús y que habitualmente dan con respuestas de raíz confesional (Jesús es el Mesías ...el Hijo de Dios o ....un profeta). Todo su análisis intenta producir, de modo renovado, un encuentro personal que suscite una reacción semejante a la de aquellos interlocutores contemporáneos a Jesús, que lo creyeron verdadero testigo de una nueva vida.

- En tercer lugar, también las cristologías contemporáneas determinan —en cierta medida - al intelectual, especialista o teólogo que las aborda. El jesuita se detiene en las propuestas cristológicas de Pannenberg, Küng y Kasper (Segundo, 1982b: 43-45). Para ellos, la cristología necesariamente se levanta sobre los cimientos de la sobriedad, la imparcialidad y la neutralidad. Así, se busca despejar cualquier intento

13 No queremos dejar de señalar que en la obra que analizamos, El Hombre de hoy..., también dedica un espacio al interesante análisis de la cristología subyacente en los ejercicios espirituales de San Ignacio. Al respecto, Segundo, 1982c: 671-784. 
de presentar un Jesús fruto de nuestros deseos y necesidades soteriológicas por temor a perder, tras nuestros condicionamientos humanos, al Jesús real y verdadero. Aquí la principal lucha se desarrolla contra la formulación de compromisos preteológicos, creyendo que éstas se evitan si tan sólo el hombre se limita a colocarse frente a Jesús sin deseos, sin anhelos, sin esperanzas y sin preguntas. Tal como una tabula rasa.

Pero ya hemos descubierto, desde los preámbulos hermenéuticos que ésta es una empresa imposible para todo sujeto que decida conocer en cuanto tal. La pre-comprensión, las opciones previas y el mundo significativo humano son difíciles de aislar en lo gnoseológico. De modo que la ambición de un hombre desnudo de prejuicios es desmedida e irreal. Por eso Juan Luis Segundo descansa en su apuesta inicial y no teme afirmar que «si hemos tenido éxito en nuestra función 'anticristológica', Jesús de Nazaret hablará lenguajes muy diferentes. Habremos liberado los significados que tiene para el hombre su vida y su mensaje» (Segundo, 1982b: 66).

\section{Con(in)clusión}

Desde la mirada aportada por el jesuita uruguayo es fácil divisar cómo la figura de Jesús se ha dejado decir, desde el inicio de los testimonios evangélicos hasta la actualidad, a través de un canal repleto de categorías e hipótesis de sentido. Ciertamente, en nuestro tiempo más cercano y en la proximidad de nuestra región, Juan Luis Segundo ha sido ese primer «hombre de hoy ante Jesús de Nazaret» que ha cumplido con la tarea, siempre escasa, de no limitar el significado de Jesús al alcance de unos pocos adoctrinados, sino de hacerlo extensivo a muchos. Y justamente esas múltiples lecturas segundarianas, que construyeron una anti-cristología a partir de las tres claves hermenéuticas, han transportado a Jesús desde su originaria Galilea hasta el hombre de hoy. Así el Nazareno se ha vuelto susceptible de encuentro para el sujeto que vivencia la tensión social y el conflicto político, ante quien se descubre en su intimidad de hombre no reconciliado y ante quien palpa en este cosmos amplio un tiempo que corre deprisa hacia un nuevo porvenir.

Ahora, como si fuera el turno que se sucede en una rueda, nos toca incluirnos en cuanto hombres y mujeres de hoy ante Jesús de Nazaret con los anhelos y las urgencias práxicas de esta hora y con la disposición de recorrer ese círculo de innumerables lecturas que nos libera del Evangelio que mata y nos hace aprender a aprender. Tal vez en alguno de sus giros nos alumbre el sentido, se afiance la búsqueda, se creen 
umbrales originales y así despierte en nosotros, la nueva humanidad que es apuesta de todos.

\section{REFERENCIAS}

-Cabestrero, T. (1978). Diálogos sobre la Iglesia en América Latina. Bilbao: Descleé de Brouwer.

-Celli, M. E. (2010). Presentación de Juan Luis Segundo. En J. L. Segundo, ¿Qué mundo? ¿Qué hombre? ¿Qué Dios? (págs. IX-XXIV). Buenos Aires: Docencia.

-De Santa Ana, J. (1997). La reflexión Teológica de Juan Luis Segundo: dogmática, rigurosa y pastoral. Cuadernos de Teología (16), 69-85.

-González Faus, J. I. (1985). ¿Dos Teologías de la Liberación? Actualidad Bibliográfica de Filosofía y Teologia (42), 264-268.

-González Faus, J. I. (1989). Un Prólogo que no lo es. En J. L. Segundo, El Dogma que libera. Fe, revelación y Magisterio Dogmático (págs. 13-23). Santander: Sal Terrae.

-Jiménez Limón, J. (1990). Dos proyectos teológicos: Metzy y Segundo. Pagar el precio y dar razón de la esperanza cristiana. Barcelona: Herder.

-Kuhn, F. (1999). Acceso a Jesús: caminos para el hombre de hoy. Introducción al Análisis de la Cristología Fundamental de Juan Luis Segundo, Anatéllei (1), 17-40.

-Segundo, J. L. (1971a). Qué es un cristiano. Montevideo: Mosca Hnos.

-Segundo, J. L. (1971b). Liberación de la Teología. Buenos Aires: Carlos Lohlé.

-Segundo, J. L. (1975). Condiciones Actuales de la Reflexión Teológica en Latinoamérica. En Encuentro Latinoamericano de Teología (Ed.), Liberación y Cautiverio. Debates en torno al método de la Teología en América Latina (págs. 91-101). México: Librería Parroquial.

-Segundo, J. L. (1977). Perspectivas para una Teología Latinoamericana. Perspectiva Teológica (9), 9-25.

-Segundo, J. L. (1982a). El hombre de hoy ante Jesús de Nazaret (Tomo I). Madrid: Cristiandad.

-Segundo, J. L. (1982b). El hombre de hoy ante Jesús de Nazaret (Tomo II/1). Madrid: Cristiandad.

-Segundo, J. L. (1982c). El hombre de hoy ante Jesús de Nazaret (Tomo II/2). Madrid: Cristiandad.

-Segundo, J. L. (1984). Teología Abierta (Tomo III). Madrid: Cristiandad.

-Segundo, J. L. (1986). La Opción por los pobres como clave hermenéutica para entender el Evangelio. Sal Terrae (74), 473-482.

-Segundo, J. L. (1989). El Dogma que libera. Fe, revelación y Magisterio Dogmático. Santander: Sal Terrae.

-Segundo, J. L. (1991). La historia perdida y recuperada de Jesús de Nazaret. De los Sinópticos a Pablo. Santander: Sal Terrae. 
-Segundo, J. L. (1992). Revelación, Fe, Signos de los tiempos. En I. Ellacuría \& J. Sobrino (Eds.), Mysterium Liberationis. Conceptos Fundamentales de la Teología de la Liberación (págs. 443-466). Madrid: Trotta.

-Sobrino, J. (1996). Ateísmo e idolatría en la teología de Juan Luis Segundo S.J. Revista Latinoamericana de Teología (37), 3-10.

Sumario: Introducción; 1.Preámbulos hermenéuticos para el acceso a Jesús de Nazaret; 1.1. Actitud hermenéutica del sujeto (Aspecto antropológico); 1.2. Conciencia hermenéutica de tres distancias (Aspecto gnoseológico); 1.2.1. Distancia entre el Jesús-Jesús y el Jesús testimoniado; 1.2.2. Distancia entre los testimonios neotestamentarios de Jesús, 1.2.3. Distancia entre Jesús de Nazaret y el acceso subjetivo del hombre de hoy a su figura; 1.3 La clave hermenéutica (Aspecto metodológico); 2.La propuesta anti-cristológica de Juan Luis Segundo; Con(in)clusión; Referencias. 